Note

\section{A Novel Kauranoid Isolated from Gibberella fujikuroi}

\author{
Noboru MUROFUSHI \\ Department of Agricultural Chemistry, \\ The University of Tokyo, \\ Bunkyo-ku, Tokyo 113, Japan \\ Received October 16, 1981
}

In the process of surveying the metabolites produced by Gibberella fujikuroi, a new kauranoid was isolated. I report here its structural determination.

An ethyl acetate-soluble neutral fraction was obtained from the culture filtrate of $G$. fujikuroi and several known kaurenoids were isolated by the application of several purification procedures. In the fraction containing $7 \beta$ hydroxykaurenolide, an unknown kaurenoid-like compound was detected, its $R f$ value being a little higher than that of $7 \beta$-hydroxykaurenolide on thin layer chromatography (TLC). Separation by preparative TLC, followed by recrystallization from dichloromethane- $n$-hexane gave a crystalline compound (1), mp $197 \sim 198^{\circ} \mathrm{C}$.

The high resolution mass spectrum of $\mathbf{1}$ indicated its molecular formula to be $\mathrm{C}_{20} \mathrm{H}_{32} \mathrm{O}_{2}\left(\mathrm{M}^{+}\right.$: calcd. 304.2400 , found 304.2429). The IR spectrum of 1 revealed a hydroxyl absorption at $3420 \mathrm{~cm}^{-1}$ but not any carbonyl band. The mass spectrum of trimethylsilylated 1 gave a molecular ion peak at $m / z 376$, indicating the presence of only one hydroxyl group in 1 . The ${ }^{1} \mathrm{H}$ NMR spectrum* showed the presence of four tertiary methyl groups $(\delta 0.85$, $0.88,1.10,1.36,3 \mathrm{H}, \mathrm{s})$ and the absence of an unsaturated bond. The ${ }^{13} \mathrm{C}$ NMR spectrum of 1 showed the presence of four methyls, seven methylenes, five methines and four carbons carrying no hydrogen atom. These observations indicate that $\mathbf{1}$ is a diterpene with a five-ring system where an ether ring is included. Assuming that $\mathbf{1}$ belongs to the kaurene derivatives, which are major metabolites of $G$. fujikuroi, the structure of $\mathbf{1}$, based on its spectral features was determined as follows.

Four methyls were allocated to 4-C (two methyls), 10-C and 16-C, and an ether linkage was placed on 16-C and another carbon, the possible position of which is $11-\mathrm{C}$ or 12-C. 11-C is more likely, based on the fact that the signal at $\delta 4.45$ (broad singlet with triplet-like shoulders, $J=$ $3.4 \mathrm{~Hz}, W_{1 / 2}=8.5 \mathrm{~Hz}$ ) is very close to the $11-\mathrm{H}$ signal of Pterokaurane $L_{5}(2, \delta 4.42 \text {, broad } \mathrm{t}, J=2.5 \mathrm{~Hz})^{1)}$ in the ${ }^{1} \mathrm{H}$ NMR spectra measured in deuteriopyridine.

1 was treated with mesyl chloride in pyridine to give a mesylate (3, NMR: $\delta 3.03,3 \mathrm{H} \mathrm{s} ; \delta 4.61,1 \mathrm{H} \mathrm{dd}, J=6 \mathrm{~Hz}$, $12 \mathrm{~Hz})$, which was refluxed in collidine to give an olefin $(\mathbf{4}$, NMR: $5.33,1 \mathrm{H} \mathrm{dd}, J=10 \mathrm{~Hz}, 3 \mathrm{~Hz} ; \delta 5.65,1 \mathrm{H}, \mathrm{dd}, J=$ $10 \mathrm{~Hz}, 2 \mathrm{~Hz}$ ). Catalytic reduction of 4 gave 5 , which showed no change either under the concentrated acidic condition or by treatment with oxidation reagents. 4 was treated with osmic acid to give a diol (6, NMR: $\delta 3.40,1 \mathrm{H} \mathrm{d}, J=3 \mathrm{~Hz} ; \delta 3.90,1 \mathrm{H} \mathrm{dd}, J=12 \mathrm{~Hz}, 3 \mathrm{~Hz})$ in which the vicinal hydroxyls are in $\beta$-configuration by the attack of the reagent from the less hindered $\beta$ side. 6 was treated with sodium periodate to give a dialdehyde (7) in which the one aldehyde group links to a tertiary carbon and the other to a quaternary carbon (NMR: $\delta 9.66,1 \mathrm{H} s ; \delta 9.83,1 \mathrm{H} \mathrm{d}, J=5 \mathrm{~Hz}$ ). These results indicate that a hydroxyl group in 1 exists in 6-C or 7-C. In this alternative, the 7-hydroxyl with $\alpha$ configuration (equatorial) is more valid, based on the coupling pattern of the carbinol proton in the NMR spectrum $(\delta 3.51,1 \mathrm{H} \mathrm{dd}, J=10 \mathrm{~Hz}, 4.8 \mathrm{~Hz})$. This conclusion was substantiated by a comparison of the $7-\mathrm{H}$ signal in the NMR spectrum of $\mathbf{1}$ measured in deuteriopyridine $(\delta 3.77,1 \mathrm{H} \mathrm{dd}, J=11.2 \mathrm{~Hz}, 4.4 \mathrm{~Hz})$ with that of 8

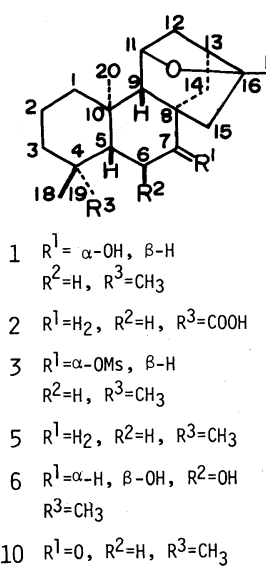

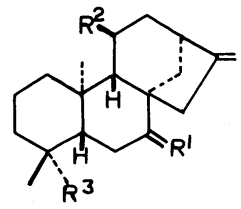

$8 R^{1}=\alpha-O H, \beta-H$

$\mathrm{R}^{2}=\mathrm{H}, \quad \mathrm{R}^{3}=\mathrm{CH}_{2} \mathrm{OH}$

$9 \mathrm{R}^{\mathrm{l}}=0, \mathrm{R}^{2}=\mathrm{H}, \mathrm{R}^{3}=\mathrm{COOH}$

$11 R^{1}=\alpha-O H, B-H$

$\mathrm{R}^{2}=\mathrm{OH}, \mathrm{R}^{3}=\mathrm{CH}_{3}$

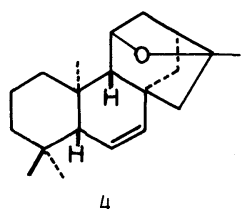

4

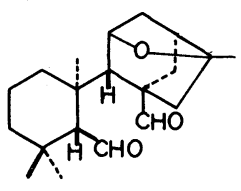

7

* NMR data in this paper are those measured in deuteriochloroform unless otherwise stated. 
Table I. Assignments of Signals in NMR SPECTRUM OF 1 MEASURED IN $\mathrm{CDCl}_{3}$

Long range coupling was observed between $11-\mathrm{H}$ and $13-\mathrm{H}$, and between $14 \alpha-\mathrm{H}$ and $15 \beta-\mathrm{H}$.

\begin{tabular}{lcll}
\hline $\begin{array}{c}\text { Assigned } \\
\text { proton }\end{array}$ & $\begin{array}{c}\text { Chemical } \\
\text { shift (ppm) }\end{array}$ & $\begin{array}{c}\text { Shape of } \\
\text { signal }\end{array}$ & $\begin{array}{c}\text { Coupling } \\
\text { const. (Hz) }\end{array}$ \\
\hline $6 \alpha-\mathrm{H}$ & 1.33 & $\mathrm{q}$ & 10.7 \\
$6 \beta-\mathrm{H}$ & 1.72 & $\mathrm{dd}$ & $4.8,10.7$ \\
$7-\mathrm{H}$ & 3.53 & $\mathrm{dd}$ & $4.8,10.7$ \\
$9-\mathrm{H}$ & 1.49 & br. s & \\
$11-\mathrm{H}$ & 4.35 & br. s & $W_{1 / 2}=9.3$ \\
$12 \alpha-\mathrm{H}$ & 2.11 & $\mathrm{~d}$ & 11.5 \\
$12 \beta-\mathrm{H}$ & 1.93 & $\mathrm{~m}$ & \\
$13-\mathrm{H}$ & 2.26 & $\mathrm{t}$ & 6.3 \\
$14 \alpha-\mathrm{H}$ & 1.65 & $\mathrm{dd}$ & $3.7,12.3$ \\
$14 \beta-\mathrm{H}$ & 1.75 & $\mathrm{dd}$ & $6.3,12.3$ \\
$15 \alpha-\mathrm{H}$ & 1.83 & $\mathrm{~d}$ & 11.5 \\
$15 \beta-\mathrm{H}$ & 1.48 & $\mathrm{dd}$ & $3.7,11.5$ \\
\hline
\end{tabular}

$(\delta 3.67,1 \mathrm{H} \mathrm{dd}, J=11.7 \mathrm{~Hz}, 3.9 \mathrm{~Hz}$ ), which was obtained from 7-oxokaurenoic acid ${ }^{2)}(9)$ by a lithium aluminum hydride reduction. Further, 9 and the oxidation product (10) of 1 revealed a similar Cotton effect (in methanol, $\mathbf{1 0}$, $294 \mathrm{~nm},[\theta]+8600 ; 9,294 \mathrm{~nm},[\theta]=+9500)$ in their CD spectra. Thus, the structure of 1 , ent $-11 \alpha, 16 \alpha$-epoxy-7 $\beta$ hydroxykaurane, was established. In addition the intensive ${ }^{1} \mathrm{H}$ NMR studies, including spin-decoupling experiments, further confirmed the structure, as shown in the accompanying Table I.

Although 1 was isolated from the extract of a culture filtrate of $G$. fujikuroi, the possibility that $\mathbf{1}$ is an artifact from 11 remains. This is because some $11 \beta$-hydroxykaurenoids isolated from liverwort, ${ }^{3)}$ fern ${ }^{1)}$ and seed plant, ${ }^{4)}$ and gibberellin $A_{35}{ }^{5)}$ which has the same moiety, were found to be converted into compounds having the $11 \sim 16$ ether linkage by treatment with acid., ${ }^{1,3}$ ) However, the occurrence of $\mathbf{1 1}$ in the culture filtrate of $G$. fujikuroi has not yet been confirmed.

Some kaurenoids obtained as metabolites of $G$. fujikuroi have an ent-7 $\alpha$-hydroxyl and/or an ent-11 $\beta$-hydroxyl group and their configurations opposite to those in $\mathbf{1}$ should be noted. Furthermore, the stage of hydroxylation to the ring carbons in ent-kaurene is of interest. Generally it occurs after the oxidation of 19-C but the occurrence of 1 (or 11) suggests another possible metabolic route of entkaurene in the fungus.

Acknowledgments. The author expresses his thanks to Professor N. Takahashi, The University of Tokyo for valuable discussions, to $\mathrm{Dr}$. $\mathrm{H}$. Seto and $\mathrm{Mr}$. $\mathrm{K}$. Furihata, The Institute of Applied Microbiology, The University of Tokyo for the $400 \mathrm{M} \mathrm{Hz}$ NMR measurement and to Kyowa Hakko Co., Ltd. for the supply of crude extract from $G$. fujikuroi.

\section{REFERENCES}

1) T. Murakami, H. Iida, N. Tanaka, Y. Saiki, C-M. Chen and Y. Iitaka, Chem. Pharm. Bull., 29, 675 (1981).

2) R. H. B. Galt and J. R. Hanson, Tetrahedron, 22, 3185 (1966).

3) I. Benes, V. Benesova and V. Herout, Collect. Czech. Chem. Commun., 42, 1229 (1977).

4) W. Herz and R. P. Sharma, J. Org. Chem., 41, 1021 (1976).

5) H. Yamane, I. Yamaguchi, N. Murofushi and N. Takahashi, Agric. Biol. Chem., 38, 649 (1974). 